\title{
Nanoindentation and AFM studies of PECVD DLC and reactively sputtered Ti containing carbon films
}

\author{
A PAUSCHITZ, J SCHALKO ${ }^{\dagger}$, T KOCH ${ }^{\dagger \dagger}$, C EISENMENGER-SITTNER ${ }^{\dagger \dagger \dagger}$, \\ S KVASNICA ${ }^{\dagger, \S}$ and MANISH ROY* \\ Austrian Centre of Competence for Tribology, Viktor Kaplan-Straße 2, A 2700 Wiener Neustadt, Austria \\ *Defence Metallurgical Research Laboratory, Hyderabad 500 058, India \\ ${ }^{\dagger}$ Institute of Industrial Electronics and Material Science, ${ }^{\dagger \dagger}$ Institute of Material Science and Testing, ${ }^{\dagger \dagger}$ Institute of \\ Solid State Physics, ${ }^{\S}$ Boltzman Institute of Biomedical Microtechnology, Vienna University of Technology, A 1040 \\ Vienna, Austria
}

MS received 23 April 2003

\begin{abstract}
Amorphous carbon film, also known as DLC film, is a promising material for tribological application. It is noted that properties relevant to tribological application change significantly depending on the method of preparation of these films. These properties are also altered by the composition of the films. In view of this, the objective of the present work is to compare the nanoindentation and atomic force microscopy (AFM) study of diamond like carbon (DLC) film obtained by plasma enhanced chemical vapour deposition (PECVD) with the $\mathrm{Ti}$ containing amorphous carbon ( $\mathrm{Ti} / \mathrm{a}-\mathrm{C}: \mathrm{H}$ ) film obtained by unbalanced magnetron sputter deposition (UMSD). Towards that purpose, DLC and $\mathrm{Ti} / a-\mathrm{C}: \mathrm{H}$ films are deposited on silicon substrate by PECVD and UMSD processes, respectively. The microstructural features and the mechanical properties of these films are evaluated by scanning electron microscopy (SEM), transmission electron microscopy (TEM), nanoindentation and by AFM. The results show that the PECVD DLC film has a higher elastic modulus, hardness and roughness than the UMSD Ti/a-C : $\mathrm{H}$ film. It also has a lower pull off force than Ti containing amorphous carbon film.
\end{abstract}

Keywords. Carbon films; nanoindentation; topography.

\section{Introduction}

Diamond-like carbon (DLC) film is considered to be a potential coating material for several varieties of tribological applications because of its high hardness (Dean and Chalamala 1999), good thermal conductivity (Robertson 2002), low friction coefficient (Donnet 1996), excellent wear resistance (Zehnder and Patscheider 2000) and chemical inertness (Wu et al 1992). Diamond films deposited by chemical vapour deposition (CVD) process exhibit high surface roughness mainly because of their columnar growth (Haubner and Lux 1993). High roughness of this film inhibits its application (Kohzaki et al 1992; Miyoshi et al 1992) in many fields such as microelectronics and optical components.

Amorphous hydrogenated carbon film obtained by physical vapour deposition (PVD) process has improved roughness without any loss of tribological properties. However, several such films have poor adhesion with the substrate. Metal containing hydrogenated amorphous carbon film, on the contrary, shows reduced internal stress (Holmberg and Mathews 1994), improved adhesion (Monaghan et al 1993) and reduced film's sensitivity to humidity

\footnotetext{
*Author for correspondence
}

(Demigan and Klages 1991). Ti containing DLC is particularly suitable for biomedical application because of its enhanced biocompatibility (Butter et al 1995).

In view of the above, the present work is undertaken to compare the mechanical properties such as hardness, elastic modulus, surface roughness etc of thin DLC films deposited by CVD process and thin Ti containing amorphous carbon films obtained by UMSD process. This work is aimed at possible application of the films for micro electromechanical systems (MEMS).

\section{Experimental}

\subsection{Deposition of diamond like carbon film}

DLC film was deposited in a parallel plate plasma enhanced chemical vapour deposition system (PECVD). Schematic representation of the system is given in figure 1 . The system is equipped with a vacuum unit and a radio frequency (RF) plasma generator. The vacuum system consists of rotary vane pump and turbo molecular pump. In this system the metal electrodes are encapsulated into a quartz glass. Such encapsulation enables separate vacuum of the inner electrode area and prevents incorporation of metal in the film. The deposition was carried out 
on a silicon substrate from a mixture of $\mathrm{CH}_{4}$ and $\mathrm{H}_{2}$. The flow of the gas was controlled through a MKS mass flow controller. The important deposition parameters are listed in table 1. Further description about the deposition process is available elsewhere (Schalko 2001).

\subsection{Deposition of Ti containing amorphous carbon film}

Film deposition was carried out in a high vacuum system (figure 2) consisting of Viton-sealed 201 cylindrical vacuum chamber equipped with a load-lock system for sample introduction without interruption of vacuum. System is pumped down by turbomolecular pump (Alcatel ATP400, $450 \mathrm{l} / \mathrm{s}$ ) and a rotary vane pump to base pressure of $2 \times$

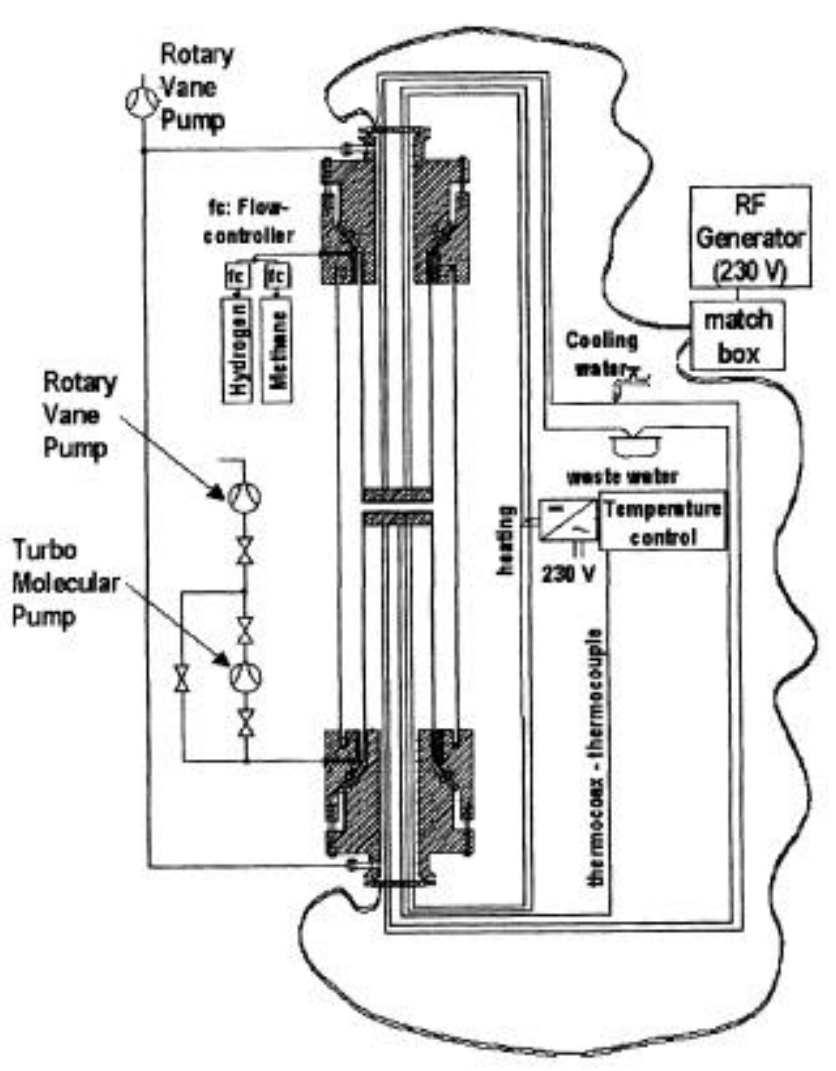

Figure 1. Schematic diagram of PECVD process for depositing DLC film.

Table 1. Deposition parameters of PECVD carbon film.

\begin{tabular}{llc}
\hline Deposition parameter & Unit & Value \\
\hline RF power & $(\mathrm{W})$ & 300 \\
Substrate temperature & $\mathrm{K}$ & 1173 \\
Mass flow methane & $\mathrm{sccm}$ & $0 \cdot 3$ \\
Pressure & Torr & 10 \\
Mass flow hydrogen & $\mathrm{sccm}$ & 150 \\
Deposition time & $\mathrm{min}$ & 240 \\
\hline
\end{tabular}

$10^{-5} \mathrm{~Pa}$ and process pressure of $0.5 \mathrm{~Pa}$ is adjusted after introducing process gases $\left(\mathrm{Ar}, \mathrm{CH}_{4}\right)$ using a throttle valve installed between the reactor and the turbo molecular pump. Gas flow rates were adjusted using mass flow controllers. Ar flow rate was held constant at $3 \mathrm{sccm}$ while the monomer $\left(\mathrm{CH}_{4}\right)$ flow rate varied between $0-3 \mathrm{sccm}$ and was feedback-controlled by optical emission spectroscopy (OES).

An unbalanced magnetron with $80 \mathrm{~mm}$ diameter polycrystalline Ti target $(99.6 \%$ purity) cathode was installed in upside down position (figure 1). Detailed description of the cathode is given elsewhere (Kvasnica et al 2001a). Plasma was generated using d.c. power source (Advance Energy Pinnacle Plus $5 \mathrm{~K}$ ) operating in constant current mode $(I=0.4 \mathrm{~A})$. Films were deposited on a silicon substrate located on a floating, cooled substrate holder $\left(20^{\circ} \mathrm{C}\right)$, which was located at the axis $6 \mathrm{~cm}$ apart from the magnetron target. The films grown in this manner were subjected to ion bombardment. Balance between the sputtering of the polycrystalline $\mathrm{Ti}$ target and positioning of the magnetron target surface and PECVD deposition under ion bombardment in the substrate region was established by locking monomer flow rate control signal to the optical emission signal of Ti atoms (Kvasnica et al 2001b). The deposition rate was monitored by a quartz microbalance positioned $2 \mathrm{~cm}$ away from the sample centre. Typical process parameters are listed in table 2. Bulk atomic Ti concentrations of deposited films measured by EDX vary in the range $2-100 \%$ and the oxygen concentration of the bulk is negligible. Repeated experiments using emission spectroscopy/EDX calibration curve show excellent reproducibility within $2 \%$.

\subsection{Characterization of the films}

The morphology of the DLC film obtained by PECVD was observed under scanning electron microscopy (SEM). In addition the film was examined by Raman spectroscopy. The microstructure of the $\mathrm{Ti}$ containing amorphous film obtained by UMSD technique was evaluated by transmission electron microscopy (TEM). For that purpose $50 \mathrm{~nm}$ thin films were deposited on a carbon foil supported by $\mathrm{Cu}$ grids. The hardness and the elastic modulus of the films were determined with the help of an instrumented indentation tester equipped with a Berkovich diamond indenter. The holding time of indentation was $60 \mathrm{~s}$ in all cases. The reported hardness and elastic modulus were average values of 10 indentations for each sample. The elastic modulus was determined using a procedure enumerated by Oliver and Pharr (1992). The elastic modulus was calculated employing (1) as given below

$$
\frac{1}{E_{\mathrm{r}}}=\frac{\left(1-\mathrm{v}^{2}\right)}{E}+\frac{\left(1-v_{\mathrm{i}}^{2}\right)}{E_{\mathrm{i}}},
$$

and $E_{\mathrm{r}}$ is given by 


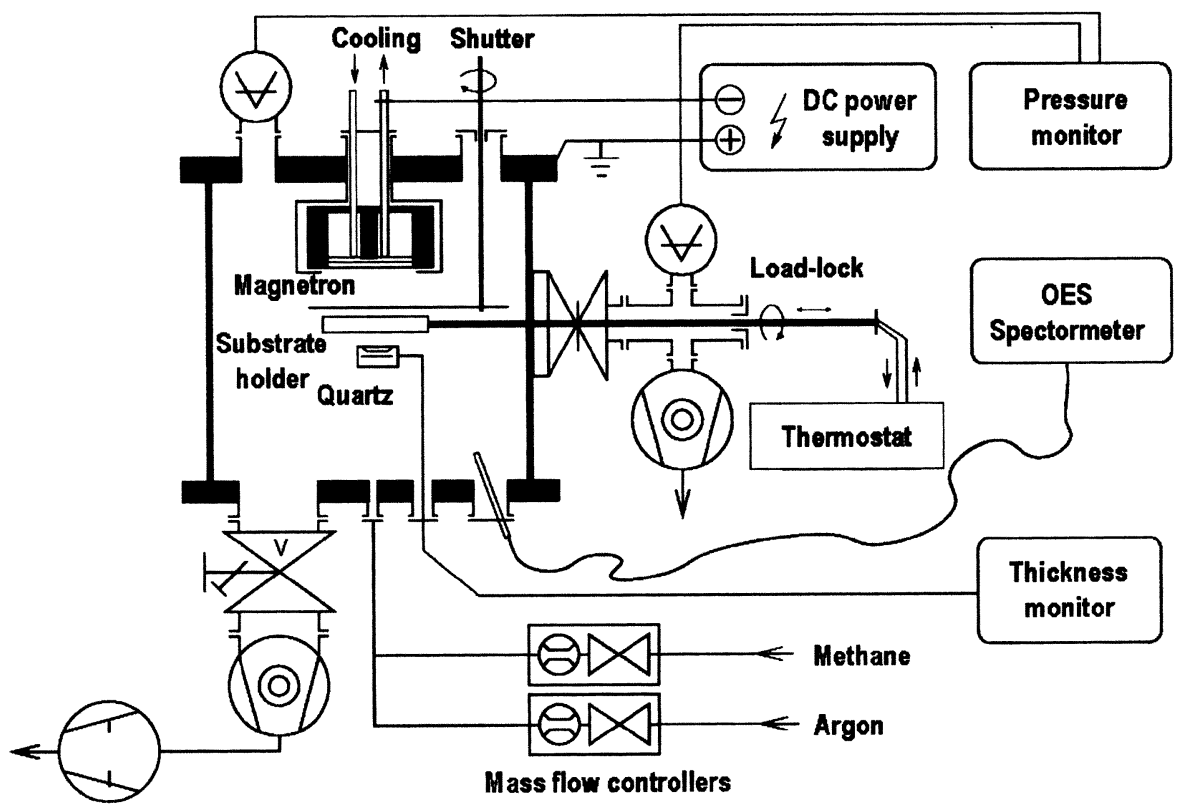

Figure 2. Schematic diagram of d.c. unbalanced magnetron sputtering process for depositing $\mathrm{Ti} / a-\mathrm{C}: \mathrm{H}$ film.

Table 2. The deposition parameter of UMSD Ti/a-C : H films.

\begin{tabular}{llc}
\hline Deposition parameter & Unit & Value \\
\hline Total pressure & $\mathrm{Pa}$ & $0 \cdot 5$ \\
Ar flow rate & $\mathrm{sccm}$ & 3 \\
$\mathrm{CH}_{4}$ flow rate & $\mathrm{sccm}$ & $0-3$ \\
Substrate temperature & $\mathrm{K}$ & $293 \mathrm{~K}$ \\
Substrate (self) bias voltage & Volts & 20 \\
Discharge current & Amps & $0 \cdot 4$ \\
Discharge voltage & Volts & $300-430$ \\
\hline
\end{tabular}

$$
E_{\mathrm{r}}=\frac{0 \cdot 89 S}{\sqrt{A}},
$$

where, $S$ is the slope of the initial part of the unloading curve, $A$ the contact area between the indenter and the substrate, $E$ and $E_{\mathrm{i}}$, are the elastic modulus and $v$ and $v_{\mathrm{i}}$ are the poisson ratio of the film and the indenter, respectively. The coated samples are examined with AFM. The topography of all the samples for a scanned area of $5 \times$ $5 \mu \mathrm{m}$ are evaluated for a set point of $10 \mathrm{nA}$ and a scan rate of $10 \mathrm{~mm} / \mathrm{s}$.

\section{Results and discussion}

The SEM image of the coated layer from the DLC film obtained by PECVD is presented in figure 3a. From this figure it is evident that there is a continuous amorphous carbon layer. On this layer, nanocrystalline diamond is uniformly distributed making the film a kind of nano-
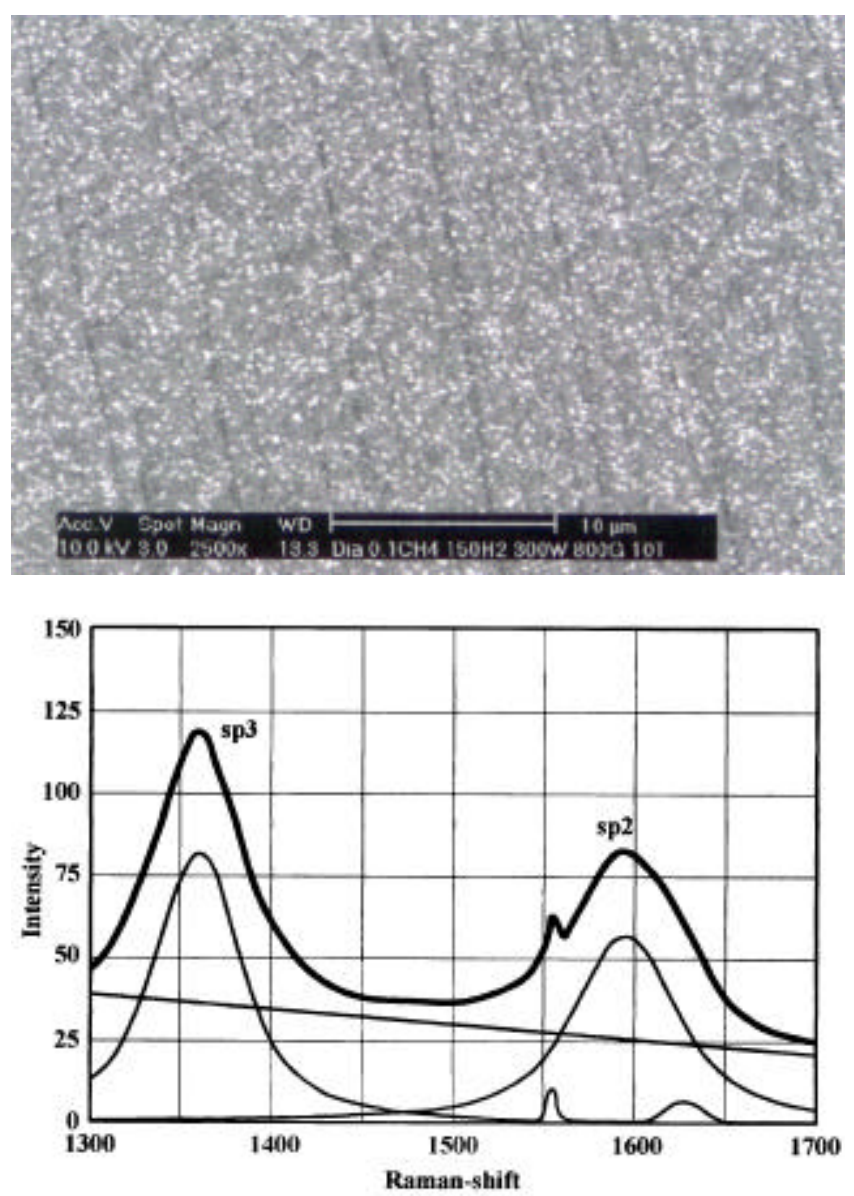

Figure 3. SEM image of the coated surface of PECVD DLC film and the corresponding Raman spectra. 
composite film. The Raman spectrum obtained by superposition of different spectral lines corresponding to the related bound energies of the DLC film is given in figure $3 \mathrm{~b}$. There are two peaks of interest. One peak is located at a wave number of $1350\left(\mathrm{~cm}^{-1}\right)$ corresponding to $s p^{3}$ carbon bond. Corresponding peak for pure diamond is located at $1330\left(\mathrm{~cm}^{-1}\right)$. The second peak is $s p^{2}$ carbon bond located at a wave number of $1600\left(\mathrm{~cm}^{-1}\right)$. The thickness of the film as measured by stylus profilometer was found to be $0.4 \mu \mathrm{m}$.

A representative bright field and dark field TEM image of the Ti containing amorphous carbon film obtained by UMSD method is given in figure 4. The corresponding diffraction pattern is also incorporated in figure 4 . Both the images indicate a grain size in $\mathrm{nm}$ range. The rings in the diffraction pattern also confirm grain sizes in the $\mathrm{nm}$ range. Furthermore, diffraction pattern suggests that the material is in crystalline form. Thus the coating investigated in the present work is nanocrystalline. The thickness of this film was $1.67 \mu \mathrm{m}$.

The load vs displacement curves obtained from both types of films are illustrated in figure 5. The maximum depth of indentation for PECVD DLC film and UMSD $\mathrm{Ti} / a-\mathrm{C}: \mathrm{H}$ film are $42.5 \mathrm{~nm}$ and $77.4 \mathrm{~nm}$, respectively. Thus the thickness of both films is more than ten times the total depth of indentation. Hence total deformation is confined to within the film confirming the fact that the hardness and elastic modulus are obtained from the films only, i.e. there is no substrate effect. For PECVD DLC film the residual displacement was $21.8 \mathrm{~nm}$ for the total
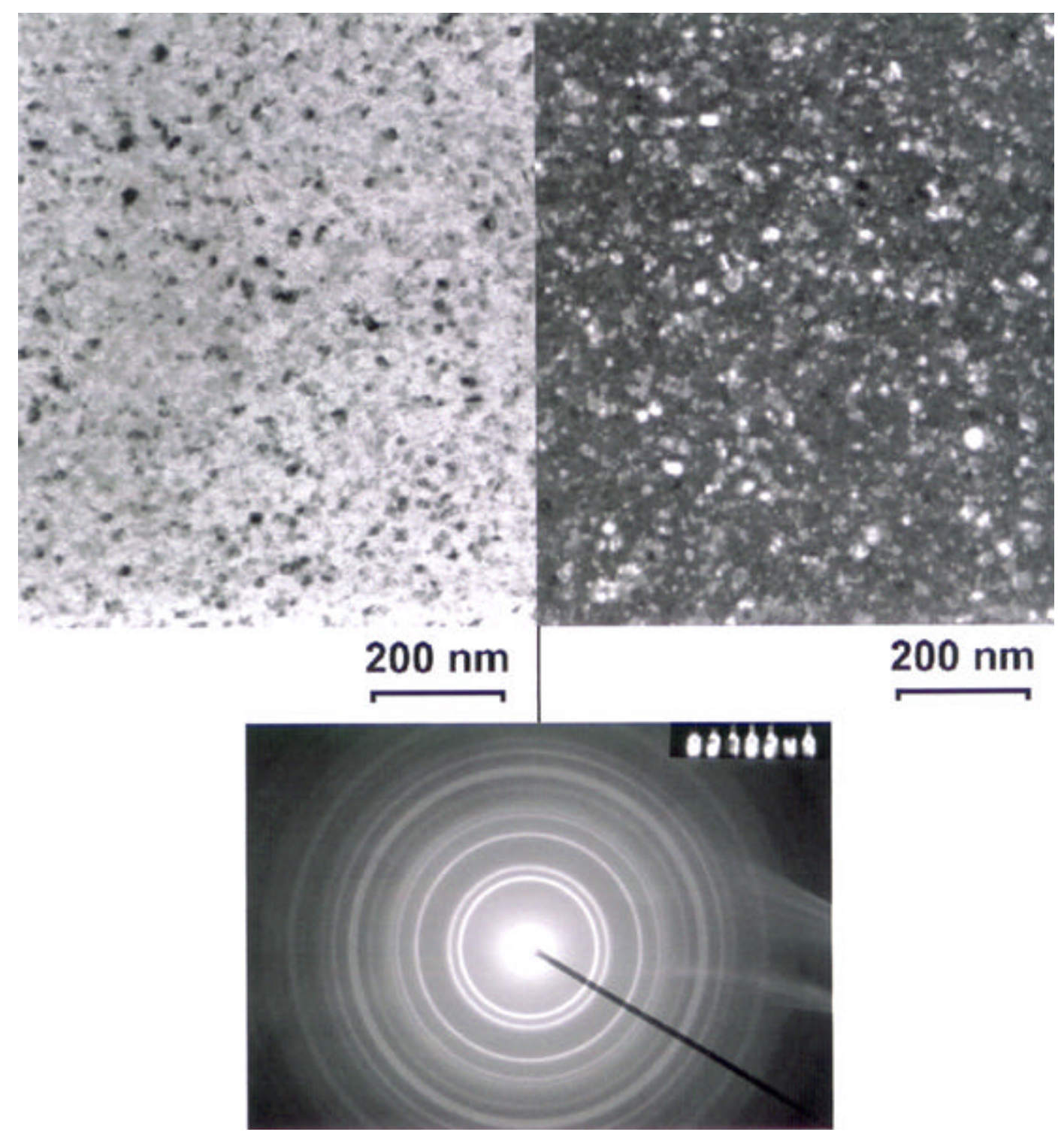

Figure 4. Bright field and dark field TEM images and the corresponding diffraction pattern of the Ti/ $a-\mathrm{C}: \mathrm{H}$ film. 
displacement of $42.5 \mathrm{~nm}$. Thus the film undergoes $49 \%$ elastic deformation and $51 \%$ plastic deformation. In contrast for $\mathrm{Ti} / \mathrm{TiC} / a-\mathrm{C}: \mathrm{H}$ film, the residual displacement is $37 \mathrm{~nm}$ for the total displacement of $77.4 \mathrm{~nm}$ indicating $52.1 \%$ elastic and $47.9 \%$ plastic deformation. Thus ductility of PECVD DLC film and UMSD Ti/TiC/a-C : H film are comparable under compressive multiaxial stress condition. At this stage it should be mentioned that the lower part of the unloading curve is significantly influenced by the geometry of the tip. Thus the estimated values of ductility are characteristic of not only the material properties but also of tip geometry. However, as the same tip is used in both cases, it is expected that the influence of tip geometry will be same in both cases confirming equal ductility for both films. The elastic modulus and the hardness of both the films are given in table 3 . Table 3 indicates that the elastic modulus of PECVD DLC film is more than four times higher than the UMSD Ti/a-C : H film. Similarly the hardness of PECVD DLC film is nearly four times the hardness of the UMSD Ti/a-C : $\mathrm{H}$ film. This
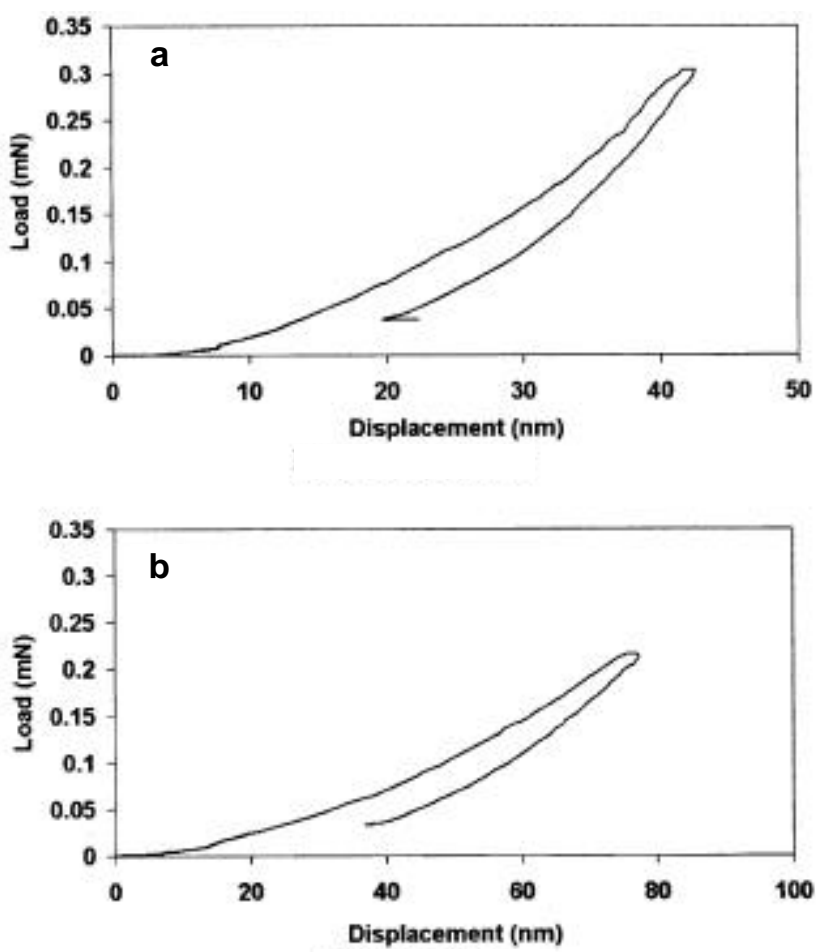

Figure 5. Load vs displacement curve for a. PECVD DLC film and b. $\mathrm{Ti} / a-\mathrm{C}: \mathrm{H}$ film.

Table 3. The elastic modulus and hardness of PECVD DLC and UMSD $\mathrm{Ti} / \mathrm{TiC} / a-\mathrm{C}: \mathrm{H}$ film.

\begin{tabular}{lll}
\hline Properties & $\begin{array}{c}\text { PECVD } \\
\text { DLC film }\end{array}$ & $\begin{array}{c}\text { UMSD Ti/TiC/a- } \\
\text { C }: \text { H film }\end{array}$ \\
\hline Elastic modulus (GPa) & $76 \cdot 9 \pm 7 \cdot 4$ & $17 \cdot 7 \pm 0 \cdot 6$ \\
Hardness (GPa) & $6 \cdot 12 \pm 0.60$ & $1 \cdot 63 \pm 0 \cdot 16$ \\
\hline
\end{tabular}

higher elastic modulus and higher hardness of PECVD DLC film can be attributed to the presence of nanocrystalline diamond.

To understand the nature of interaction between the cantilever tip and the coating, the AFM measurement is carried out in force calibration mode. Figure 6 shows the deflection of the cantilever tip as function of the position of the film surfaces. In both cases, darker line indicates tip approach and lighter line represents pulled away. The horizontal separation between point $\mathrm{A}$ where the tip is touching the film and point B where the tip is pulled off the film is a measure of the pull off (adhesive) force. The product of this horizontal distance of separation and the spring constant of the cantilever $(0.58 \mathrm{~N} / \mathrm{m})$ gives the pull off forces (Bhusan 1999). It can be seen clearly that the pull off force for $\mathrm{Ti} / a-\mathrm{C}: \mathrm{H}$ film is significantly larger than the pull off force of PECVD DLC film. These values are calculated to be $445 \mathrm{nN}$ and $76.41 \mathrm{nN}$ for $\mathrm{Ti} / a-\mathrm{C}: \mathrm{H}$ and PECVD DLC film, respectively. This fact may be related to increase of surface energy due to addition of $\mathrm{Ti}$ to the amorphous film. The presence of Ti increases the affinity of the film towards oxygen. Grischke et al (1998) found an increase of surface energy of amorphous carbon
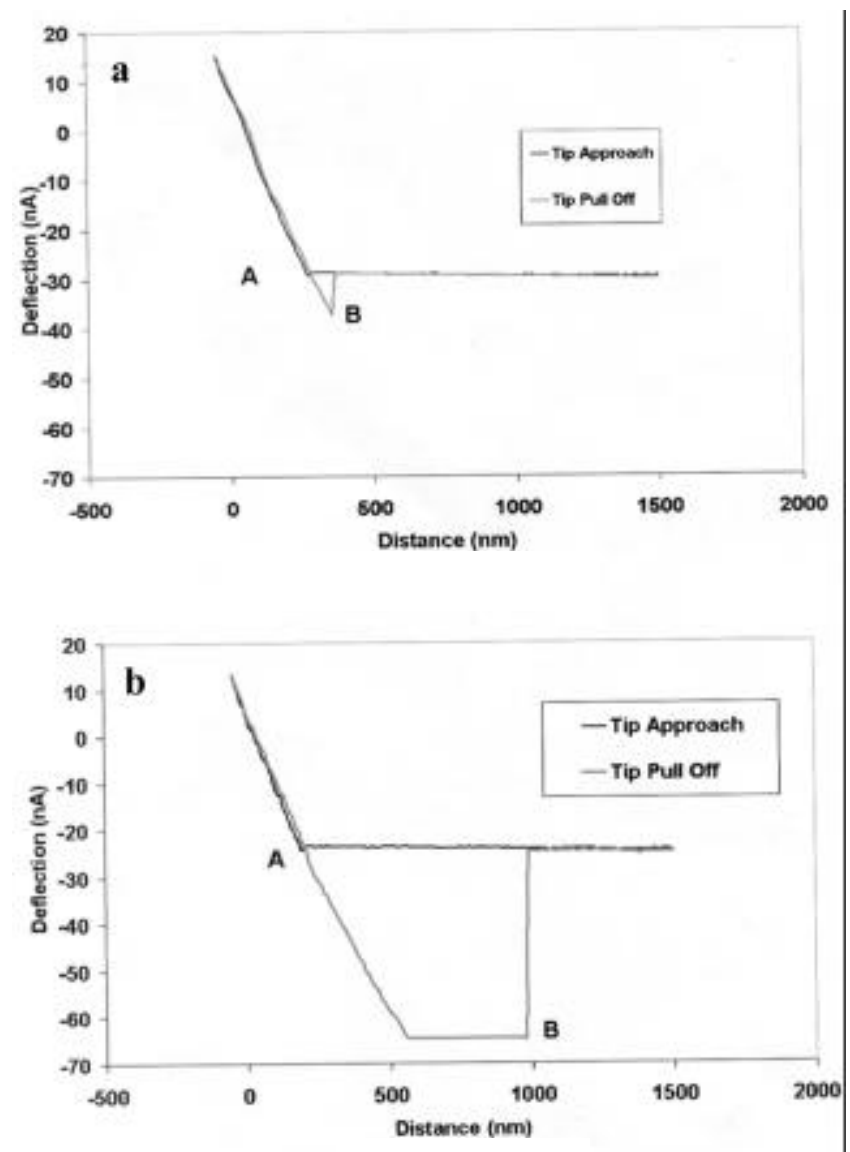

Figure 6. Pull off force curves of a. PECVD DLC film and b. $\mathrm{Ti} / a-\mathrm{C}: \mathrm{H}$ film. 
film from $41 \mathrm{mNm}^{-1}$ to $52 \mathrm{mNm}^{-1}$ with oxygen addition. Thus the $\mathrm{Ti}$ containing film has very thin oxide layer which increases the surface energy and the increased surface energy in turn increases the pull off force.

The three-dimensional topography of both the films is displayed in figure 7. The morphological peaks of the PECVD DLC films are quite sharp compared to the peaks in Ti containing carbon coating. Various important topo- graphic parameters are listed in table 4. Clearly PECVD DLC film has higher roughness than $\mathrm{Ti} / a-\mathrm{C}: \mathrm{H}$ film. It also has higher average height and higher maximum height. The average roughness of the rougher PECVD DLC film is $3.64 \mathrm{~nm}$. This roughness is more than $1 / 20$ th of the maximum depth (which is $42.5 \mathrm{~nm}$ ) of indentation on PECVD DLC film. Hence the nanoindentation process does not confirm the roughness criteria. However, if the load is
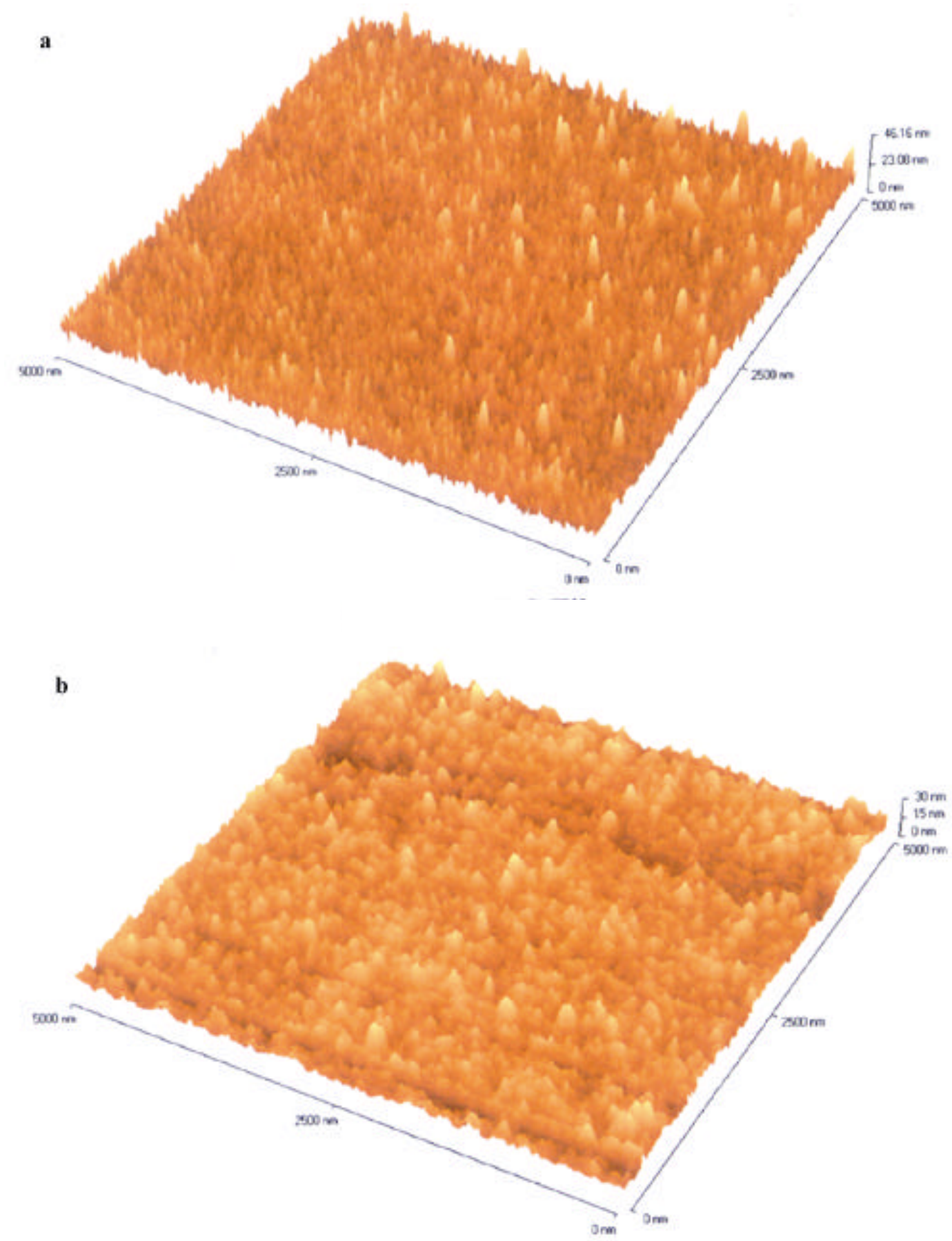

Figure 7. Surface topography of a. PECVD DLC film and b. Ti/a-C : H film. 
Table 4. The various important morphological parameters of PECVD DLC and UMSD Ti $/ a-C: H$ film.

\begin{tabular}{lcc}
\hline & $\begin{array}{c}\text { PECVD } \\
\text { DLC film }\end{array}$ & $\begin{array}{c}\text { UMSD Ti/TiC/a- } \\
\text { C }: \text { H film }\end{array}$ \\
\hline Roughness, $R_{\mathrm{a}}(\mathrm{nm})$ & $3 \cdot 64$ & $2 \cdot 65$ \\
RMS (nm) & $4 \cdot 76$ & $3 \cdot 39$ \\
Average height $(\mathrm{nm})$ & $16 \cdot 21$ & $13 \cdot 74$ \\
Maximum height $(\mathrm{nm})$ & $46 \cdot 16$ & $30 \cdot 00$ \\
\hline
\end{tabular}

increased beyond the value applied in the present case, the depth of deformation zone will extend into the substrate revealing the hardness of film/substrate system rather than the hardness of the film. In view of this, the load is maintained for a maximum depth of indentation of $42 \cdot 5 \mathrm{~nm}$.

\section{Conclusions}

(I) A comparison of the nanoindentation behaviour and AFM study of DLC film obtained by PECVD and Ti/a$\mathrm{C}: \mathrm{H}$ film obtained by UMSD is made.

(II) The elastic modulus and the hardness of PECVD DLC is nearly 4 times higher than that of UMSD $\mathrm{Ti} / a-\mathrm{C}: \mathrm{H}$ even though both films have comparable ductility.

(III) The pull off force of the tip is higher for Ti/a-C : $\mathrm{H}$ film than for DLC film.

(IV) The surface roughness of the PECVD DLC film is higher than the surface roughness of the $\mathrm{Ti} / a-\mathrm{C}: \mathrm{H}$ film at ambient condition.

\section{Acknowledgements}

This work was funded from the "Austrian Kplus-Program" and has been carried out within the "Austrian Centre of Competence for Tribology". The authors are grateful to
Prof. F Franek, Managing Director, K-plus Centre, for his constant encouragement during the course of this investigation.

\section{References}

Bhusan B 1999 Handbook of micro/nanotribology (Boca Raton, FL: CRC Press) 2nd ed.

Butter R, Allen M, Chandra L, Lettington A H and Rushton N 1995 Diamond \& Relat. Mater. 4857

Dean K A and Chalamala B R 1999 Appl. Phys. Lett. 76375

Demigan H and Klages C P 1991 Surf. Coat. Technol. 49543

Donnet C 1996 Surf. Coat. Technol. 80139

Grischke M, Hicke A, Morgenweck F and Demigan H 1998 Diamond \& Relat. Mater. 7454

Haubner R and Lux B 1993 Diamond Relat. Mater. 21277

Holmberg K and Mathews A 1994 Coat. tribology (New York: Elsevier)

Kohzaki M, Higuchi K, Noda S and Uccida K 1992 J. Mater. Res. 71769

Kvasnica S, Fasching R and Kohl F 2001a Proc. of int. symp. on plasma chemistry 15, Orleans, France

Kvasnica S, Fallman W, Biederman H, Boldyreva H and Slavínská D 2001b Deposition and characterization of Ti/C : H films, in Proc. int. symp. on plasma chemistry 15, Orleans, France

Miyoshi K, Wu R L C and Garscaden A 1992 Surf. Coat. Technol. 54/55 428

Monaghan D P, Teer D G, Logan P A, Efeoglu I and Arnell R D 1993 Surf. Coat. Technol. 60525

Oliver W C and Pharr G M 1992 J. Mater. Res. 71564

Robertson J 2002 Mater. Sci. \& Engg. R37 129

Schalko J 2001 Deposition and characterization of PECVD carbon and carbon alloy films in various modification, Ph D thesis, Vienna University of Technology, Vienna

Wu R L C, Miyoshi K, Vuppuladhadium R and Jackson H E 1992 Surf. Coat. Technol. 54/55 576

Zehnder T and Patscheider J 2000 Surf. Coat. Technol. 133134138 